\title{
O067: Poorly processed reusable dispensers for surface disinfection tissues are a possible source of infection
}

\author{
$\mathrm{G} \mathrm{Kampf}^{1,2^{*}}, \mathrm{H}$ von Baum ${ }^{3}, \mathrm{C}$ Ostermeyer ${ }^{4}$ \\ From 2nd International Conference on Prevention and Infection Control (ICPIC 2013) \\ Geneva, Switzerland. 25-28 June 2013
}

\section{Introduction}

Reusable surface disinfectant (SD) tissue dispensers are used in hospitals in many countries because they allow immediate access to soaked tissues for targeted surface decontamination.

\section{Objectives}

We determined the frequency of contaminated SD solutions in reusable dispensers and the ability of isolates to multiply in different formulations.

\section{Methods}

Dispensers with different SD were randomly collected from healthcare facilities. Solutions were investigated for bacterial contamination using standard microbiological methods. Isolates of the same species were investigated by pulsed-field gel electrophoresis (PFGE) for clonal identity. The efficacy of two SD was determined in suspension tests (EN 13727) under dirty conditions against two isolated species directly from a contaminated solution or after 5 passages without selection pressure in triplicate. Fresh use solutions of four different types of SD were contaminated with a fresh dispenser isolate to determine its survival or multiplication over 28 days.

\section{Results}

66 dispensers containing SD solutions with surface-active ingredients were collected from 15 healthcare facilities. 28 dispensers from nine healthcare facilities were contaminated with approximately $10^{7}$ cells per mL of Achromobacter species 3 (9 hospitals), Achromobacter xylosoxidans or Serratia marcescens (1 hospital each). Clonal non-

${ }^{1}$ Bode Science Center, Bode Chemie GmbH, Hamburg, Germany

Full list of author information is available at the end of the article identity was shown for 8 of 9 Achromobacter species 3 isolates. In none of the hospitals dispenser processing was adequately performed. Isolates regained susceptibility to the SD after five passages without selection pressure, for example against Achromobacter species 3 with a mean $\log _{10}$-reduction of 0.06 initially and 2.37 after 5 passages (Incidin plus $0.5 \%$ for $60 \mathrm{~min}$ ). Adapted and passaged cells were equally able to multiply in different formulations from different manufacturers with surface-active ingredients at room temperature within 7 days to a cell count of $10^{7}$ bacteria per $\mathrm{mL}$, only a formulation with additional aldehyde was able to completely kill the contamination.

\section{Conclusion}

Neglecting adequate processing of tissue dispensers has contributed to frequent and heavy contamination of use-solutions of SD based on surface active ingredients.

\section{Disclosure of interest}

G. Kampf Employee of Bode Chemie GmbH, Hamburg, Germany, H. von Baum: None declared, C. Ostermeyer Employee of Bode Chemie GmbH, Hamburg, Germany.

\section{Author details \\ ${ }^{1}$ Bode Science Center, Bode Chemie GmbH, Hamburg, Germany. ${ }^{2}$ Institute for Hygiene and Environmental Medicine, Ernst-Moritz-Arndt University, Greifswald, Germany. ${ }^{3}$ Institut für Med. Mikrobiologie und Hygiene, Universität UIm, UIm, Germany. ${ }^{4}$ Microbiology, Bode Chemie GmbH, Hamburg, Germany.}

Published: 20 June 2013

doi:10.1186/2047-2994-2-S1-067

Cite this article as: Kampf et al:: 0067: Poorly processed reusable dispensers for surface disinfection tissues are a possible source of infection. Antimicrobial Resistance and Infection Control 2013 2(Suppl 1):067. 